Relations industrielles

Industrial Relations

\title{
Le Statut des Entreprises publiques, par A.G. Delion, Collection de l'Administration nouvelle, Berger-Levrault, Paris, 1963, 268 pages.
}

\section{André Gélinas}

Volume 19, numéro 1, janvier 1964

URI : https://id.erudit.org/iderudit/1021385ar

DOI : https://doi.org/10.7202/1021385ar

Aller au sommaire du numéro

Éditeur(s)

Département des relations industrielles de l’Université Laval

ISSN

0034-379X (imprimé)

1703-8138 (numérique)

Découvrir la revue

Citer ce compte rendu

Gélinas, A. (1964). Compte rendu de [Le Statut des Entreprises publiques, par A.G. Delion, Collection de l'Administration nouvelle, Berger-Levrault, Paris, 1963, 268 pages.] Relations industrielles / Industrial Relations, 19(1), 133-133. https://doi.org/10.7202/1021385ar

Tous droits réservés (C Département des relations industrielles de l’Université Laval, 1964
Ce document est protégé par la loi sur le droit d'auteur. L’utilisation des services d’Érudit (y compris la reproduction) est assujettie à sa politique d'utilisation que vous pouvez consulter en ligne.

https://apropos.erudit.org/fr/usagers/politique-dutilisation/ 
crets utilisables pour fins de discussion et d'onalyse.

Enfin, les principoux textes législotifs pertinents ou sujet sont fournis en oppendice, soit dans leur teneur totale, soit en dé larges extraits.

Somme toute un des manuels les mieux faits et parmi les plus utiles, outant aux proticiens qu'aux étudiants en lo matière.

\section{Jean-Réal Cordin}

Le Statut des Entreprises publiques, par A G. Delion, Collection de l'Administration nouvelle, Berger-Levrault, Paris, 1963, 268 pages.

L'on n'a plus à démontrer, il me semble, l'importance des entreprises publiques dans la plupart des pays y compris ceux de I'Occident. En ce qui a trait à la France, André DELION a déjà publié plusieurs études sur le sujet, notomment, PEtat et les entreprises publiques (Sirey, Poris, 1959).

Dans Le Statut des Entreprises publiques $\gg$, I'auteur examine systématiquement et fort judicieusement les principales interrelations entre d'une part, l'entreprise publique et d'autre part, les organismes de contrôle que sont le porlement, le gouvernement et le Conseil d'Etat. En guise d'introduction, DELION donne quelques notes historiques et indique les règles relatives à la création, d̀ la notionalisotion et d̀ la disparition des entreprises publiques. L'ouvroge est très à point et fort bien rédigé

L'opproche est foncièrement formelle et juridique. Ce qui explique sans doute pourquoi I'on a ignoré le rôle des partis et celui de l'opinion publique Les discussions et les critiques sont rares. Les préoccupations d'ordre administrotif, politique et économique sous-jocentes sont rarement exprimées. II existe à cet égard un contraste frappant entre l'ouvrage de DELION et certaines études des onnées d'après guerre. notamment celles de Ventanat, de Juliot de la Morandière et de Lavergne qui mettaient en cause, sous différents aspects, l'idée même de la nationalisation. Cette idée étont mointenant devenue occeptoble il appartient ou juriste de formuler les nouvelles règles fondamentales d'organisation générale, c'est-à-dire, le stotut.

II va sans dire que I'on peut difficilement comporer le statut des entreprises publiques en Fronce et au Québec. Même si l'on fait obstraction des différences d'ordre quantitatif qui sont considérobles (en 1963, lo France comptait 150 entreprises publiques, le gouvernement canadien une quarontaine et le Québec une dizaine) il n'en reste pos moins que le contexte global est loin d'être identique. Lo planificotion économique est ici embryonnaire, les responsabilités sont portagées entre les collectivités provincioles et centrales, enfin la gestion publique commerciole est encore une source de controverses.

Sous l'angle restreint des rapports entre les entreprises publiques et les autorités de tutelle, il est vrai que nous observons ici oussi le principe de l'autonomie de gestion. Par contre, les moyens de contrôle diffèrent sensiblement. II n'y a pos ou Québec, par exemple, de commissaires de gouvernement, ni Commissions de Vérification des comptes des entreprises publiques, ni bien entendu, de Conseil d'Etot. De plus, les conseils d'administration n'obéissent pos ò lo formule de composition tripartite. Quont d la surveillance parlementaire, la nôtre frise I'insignifiance. L'Assemblée Législative n'a élaboré oucun méconisme spécial de contrôle. Evidemment, l'on peut expliquer ces différences par une foule de raisons dont certaines sont attribuables oux structures même de l'administration générale. Par contre, il fout bien dire qu'd mon sens, I'on a peu ressenti ici la nécessité d'une surveillonce plus étroite tout simplement à cause du petit nombre d'entreprises publıques. Le besoin devrait éventuellement créer l'organe.

\section{André Gélinas}

\section{Economic Analysis and Industrial Manage-} ment, par Jacques Lesourne, Prentice Holl, Inc., Englewood Cliffs, N.J., 1963, 631 pages.

$\mathrm{Ce}$ volume a déjò paru en françois en 1958 sous le titre \& Technique Economique et Gestion Industrielle $>$ II constitue une lecture probablement des plus profitables pour le futur ingénieur-économiste. En effet, nous croyons que ce livre s'odresse surtout aux ingénieurs qui se dirigent vers l'odministration de l'entreprise et qui partont désirent ocquérir une connaissonce de la théorie économique appliquée d̀ la gestion industrielle. Beaucoup d'économistes peuvent égolement tirer profit de lo formulation des principes économiques en termes mothématiques et statistiques. II ne 